\title{
Modeling and simulation in medical sciences: an overview of specific applications based on research experience in EMRI (Endocrinology and Metabolism Research Institute of Tehran University of Medical Sciences)
}

\author{
Azadeh Ebrahim-Habibi ${ }^{1}$ (D) $\cdot$ Elaheh Kashani-Amin ${ }^{1} \cdot$ Bagher Larijani $^{2}$ \\ Received: 28 September 2020 / Revised: 26 November 2020 / Accepted: 7 December 2020 \\ (C) Springer Nature Switzerland AG 2021
}

\begin{abstract}
The concomitant use of various types of models (in silico, in vitro, and in vivo) has been exemplified here within the context of biomedical researches performed in the Endocrinology and Metabolism Research Institute (EMRI) of Tehran University of Medical Sciences. Two main research aeras have been discussed: the search for new small molecules as therapeutics for diabetes and related metabolic conditions, and diseases related to protein aggregation. Due to their multidisciplinary nature, the majority of these studies have needed the collaboration of different specialties. In both cases, a brief overview of the subject is provided through literature examples, and sequential use of these methods is described.
\end{abstract}

Keywords Disease model $\cdot$ Alpha-amylase inhibitor $\cdot$ Amyloid $\cdot$ Insulin injection

\section{Introduction}

"Model" is a generic word, present in the majority (if not all) of scientific disciplines technical vocabulary, and could be represented by a simple diagram that is easily understood by a glance. It could also be a complex entity incorporating hundreds of thousands of interacting partners, that should be analyzed by an information processing system. Either simple or complex, a model is always an approximation, contains errors, and is usually a tool to be used alongside with others.

Even within a particular scientific branch, such as medical sciences, a "model" takes different forms. As an example, in the present context of COVID-19, there has been a worldwide effort to predict the spread and dynamics of the disease [1-4],

Azadeh Ebrahim-Habibi

aehabibi@sina.tums.ac.ir; azadehabibi@yahoo.fr

1 Biosensor Research Center, Endocrinology and Metabolism Molecular-Cellular Sciences Institute, Tehran University of Medical Sciences, Jalal-al-Ahmad Street, Chamran Highway, 1411713137 Tehran, Iran

2 Endocrinology and Metabolism Research Center, Endocrinology and Metabolism Clinical Sciences Institute, Tehran University of Medical Sciences, Tehran, Iran and a similar international endeavor toward finding potential drugs that would bind the virus proteins [5-7]. In both cases, sophisticated "models" were used, which have fundamentally different characteristics: one includes mathematical equations and the other is an atomistic representation of proteins.

The first modeling works that have been performed in EMRI had a mathematical nature and included modeling of angiogenesis in tumors (aiming at improving diagnostic) [8], and proposing a suitable time to test bone mass density in post-menopausal women receiving levothyroxine [9]. In the following years, different kinds of mathematical models have been used in numerous studies related with public health (e.g. [10] ) and other clinically-oriented subjects such as osteoporosis (e.g. adjusting a predictive tool to assess fracture risk in osteoporotic patients for the Iranian population) [11].

In this condensed overview, examples of specific research subjects related to medical sciences are discussed with an emphasis on the use of in vivo, in vitro, and in silico models. These subjects have been investigated by students and researchers over the past twelve years in the Modeling and Simulation in Medical Sciences (MSMS) research group of EMRI with the help and contribution of numerous collaborators inside and outside EMRI. We believe that models are important tools that upon extensive development, could 
reduce the overall cost of research, and ideally replace the need for extended testing.

\section{Glucose homeostasis and related metabolic conditions disorders}

In a recent study concerning the global burden of diseases, increase of the mortality rate and total years of life lost (YLL) due to diabetes mellitus has been observed (around 31 and 25\% respectively) between 2006 and 2016, while YLL itself had decreased (around 2\%) [12]. A worldwide rise in the prevalence of diabetes is likely, estimated to reach $10.4 \%$ by 2040 [13], and justifies the search for novel therapies to control the disease and prevent its complications.

Various molecular targets have been proposed and explored in this regard, with the aim of improving insulin's effect (e.g. by influencing beta-cells function by modulating related receptors), as well as controlling oxidative stress and inflammation to counteract beta-cells apoptosis $[14,15]$. A different approach consists of interfering with key carbohydrate digestive enzymes (glycosidases) that are responsible for the postprandial rise of blood glucose level, especially alphaglucosidase [16], and alpha-amylase [17]. Inhibitors of these enzymes could also be potentially effective in obesity. Many studies are now reporting the glycosidase inhibitory potential of plants and their active components [18]; earlier studies had also demonstrated the efficacy of flavonoids in this regard [19, 20], and analyzed putative binding modes of these compounds to the enzyme by in silico techniques [21].

During in vitro experiments, with the use of pancreatic alpha-amylase, and based on the fact that the natural compounds flavonoids were known as amylase inhibitors [22], we found trans-chalcone (flavonoids precursor) to be an inhibitor of pancreatic amylase [23]. Further experiments showed it to be also effective in vivo, on a rodent diabetic model [24] and in a mice model of fatty-liver, where the compound was able to modulate lipid profile, leptin, and glucose levels, as well as improving liver steatosis [25]; these results were comparable to what we had seen in a mice model of obesity [26]. Trans-chalcone is actually considered as a potent scaffold, whose numerous derivatives span a wide range of therapeutic properties [27, 28].

The benzothiazole thioflavin $\mathrm{T}$ (ThT), with slighter inhibitory activity in vitro, was also found to be potentially antidiabetic in vivo [29], as well as effective in weight reduction of a mice model of obesity [30]. ThT is a well-known probe for detection of amyloid structures[31], but interestingly, had also been found to extend the lifespan of $C$. elegans (as a model for studying ageing and lifespan) [32, 33], and seems to be an interesting therapeutic scaffold.

Synthetic aurones ((Z)-2-benzylidenebenzofuran-3-one derivatives), which bear structural similarity to flavonoids were also tested in vitro against pancreatic amylase as inhibitors, and subsequent in silico tests (docking) suggested their putative binding modes into the enzyme [34]. Docking was done with the use of U-Dock 1.6 program [35], with the MMFF94s force field and on MOE (Molecular Operating Environment 2012.10) and the target was PDB entry 1OSE [36] In this method, a series of ligands conformers were docked onto the target and poses with best energy were retrieved. This data could be of use for synthesizing more potent inhibitors. Recently, many natural extracts and synthetic new molecules have been investigated with regard to their alpha-amylase inhibitory properties [37-48] and this line of study seems to be promising with regard to finding effective anti-diabetic aids.

On the other hand, activators of the enzyme may potentially show an adverse effect in this regard, although hypothetically beneficial for digestive problems. Interestingly, the commercially available sweetener neohesperidin dihydochalcone (from sweet orange), which has a chalcone structural component was found to activate alpha-amylase from different sources $[49,50]$. Xanthine derivatives, pentoxyfilline, theobromine and caffeine were also found to slightly (20-30\%) increase enzyme activity[51]. To our knowledge, these should be the only small molecules that have been reported as activator of this enzyme.

In another context, sweet taste receptor (STR), a class C Gprotein coupled receptor (C GPCR), has been suggested as a drug target for designing either new low-calorie sweeteners or drugs to control metabolic condition disorders such as type II diabetes mellitus $[52,53]$. In order to design appropriate ligands for this receptor, a three-dimensional structure is needed, but since the human receptor structure is still not experimentally elucidated, in silico (molecular modeling) methods were used in this case. First, a new model of STR structure was developed [54]. Extensive docking experiments on the model revealed presence of carbohydrate binding modules as structural and functional motifs [55], which is applicable in further characterization of the binding site. Docking was performed on an ensemble of STR structures obtained by running a molecular dynamics simulation (MDS) experiment. MDS was run for $50 \mathrm{~ns}$ in YASARA program [56] using the YASARA forcefield [57]. The initial structure atoms were protonated at physiological pH, Particle Mesh Ewald (PME) was used, $8.0 \mathrm{~A}^{\circ}$ cutoff for non-bonded interactions and $4 \mathrm{fs}$ timestep were applied, hydrogen atoms were constrained and the system was at constant pressure and temperature (NPT). Based on carbon alpha RMSDs of the total MDS run, clusters were obtained based on minimum, median and maximum values. Docking was performed on these clusters with AutoDock Vina [58] on the interface present in YASARA which enabled computing H-bonds and HP-interactions, as well as minimization of the best poses to take water molecules into account. Finally, by studying interaction patterns of 316 sweet molecules as well as sweet proteins and antagonists of 
the receptor, a few compounds were suggested as putative sweet molecules or agonists for the receptor [unpublished data]. Increasing our knowledge about this receptor structure/ function and its agonists/antagonists would surely be of help in the current debate about the beneficial/detrimental effects of sweeteners [59-62].

\section{Proteins aggregation: formation of pathogenic species}

The integrity of proteins three-dimensional structures is a requirement for their normal functioning. Over disruption of their intramolecular interactions, "misfolded" proteins structures could be formed, which, depending on environmental conditions, may "aggregate" together and form stable clusters. Misfolding may happen upon mutations or other external causes, and lead to "protein diseases". Aggregates may be structured (amyloid) or unstructured (amorphous), although various intermediate forms can also be observed [63].

Amyloid formation is suggested to have a pathogenic role in a range of disorders, including Azheimer's and Parkinson disease, metabolic diseases, and diabetes [64]. In recent years, formation of structured amyloid forms has been suggested to be a generic property of proteins, which means that any protein could be potentially driven toward forming amyloids [65], and as so, be used as a model to study the process in details. Inhibiting amyloid formation or disruption of amyloid structures by small ligands has been the subject of numerous studies in the past two decades, and based on these reports, there have been attempts to classify ligands and identify the structural prerequisites that make suitable anti-amyloid compounds [66-72].

One of the research subjects that could provide useful information for drug design is the study of structural changes that occur in proteins and result onto amyloid formation. Disruption of the native and functional architecture of the protein may start from specific locations, and aggregationprone sites in proteins have an important role in triggering aggregates formation. Predicting those regions has been (and still is) the subject of multiple computational studies which have resulted onto design of various tools [73-83]. An alternative to these tools is the application of molecular dynamics simulation methods to proteins and monitor the changes that happen in their structures under various deleterious conditions. We have applied this method to insulin [84] and two forms of myoglobin (native and glycated) [85] and could spot specific regions that seem to be initiators in the structural change process. In both cases, high temperatures were employed in order to reach the unfolded state more easily [86]. For insulin, different conditions (presence and absence of $\mathrm{KCL}$ and $\mathrm{NaCL}$ ) were tested, at high temperature and acidic $\mathrm{pH}$ (obtained by changing the protonation state of the protein).
For the actual run, MOE (Molecular Operating Environment MOE.2010.10), and the implemented MMFF94x force field were used for $15 \mathrm{~ns}$ runs of each condition. To check the conformational change over time, secondary structure content was analyzed by using various methods including DSSP [87], STRIDE [88], PALSSE [89], P-SEA [90], STICK[91], and XTLSSTR [92]. For myoglobin too, the same program (MOE.2010.10), and the implemented MMFF94x force field were used. In this case, in addition to secondary structure content (computed by DSSP), structures' RMSDs were also compared in order to find the most stable regions. Our subsequent ongoing research projects focus on shorter proteins with the aim of pinpointing specific residues in well-defined secondary structure segments. These in silico methods could also provide a mean to screen potential stabilizing ligands that could counteract these structural changes to some extent [unpublished results].

In vitro methods provide the possibility to generate amyloid forms of various proteins, and to test potential antiamyloid molecules. Phenolic, polyphenolic, and other cyclic compounds have been tested in our past (collaborative) studies on various proteins including polygalacturonase, albumin [93], myoglobin [94], and insulin [95].

Molecules that were found to inhibit proteins fibrillation, were then tested in vivo, on a rodent model of AD. In order to simulate part of the AD signs, abeta amyloid is injected to the animals hippocampus, which results into plaque formation and troubles in learning. Candidate ligands that were administered to the $\mathrm{AD}$ animal models, and could attenuate their symptoms to some extent included indole and trans-chalcone [96], sylimarin [97], metformin [98], thymol [99], and eugenol [100]. Based on our experience in generating amyloid structures in insulin, we have also proposed a modification in the generation of rodent AD-like model : instead of injecting abeta amyloids to the animals brains, we used insulin amyloids which are easier formed at a lower cost [101].

Insulin amyloid formation is a problem in patients who have to inject the protein subcutaneously to control their blood glucose levels. We found that chemical modification of insulin by anhydrides at its lysine residue could attenuate its amyloid formation, while insulin still remained functional with one of the modifiers (succinic anhydride) and with another, a delayed onset of insulin action was observed [102]. In another set of experiments, we simulated the condition that is observed in diabetic patients by injecting insulin amyloid to rodents. This resulted onto formation of masses composed of adipose cells in which amyloid deposits could be observed [103]. A subsequent test showed turmeric to be effective in reducing the size of those masses [104] and further studies are now conducted in order to further develop this model and check the effect of other compounds. Recently, our method was used by other researchers to assess the effect of serine proteases on amyloid fibrils [105]. 


\section{Concluding Remarks}

In the two main research subjects that have been discussed here, interdisciplinary work was needed, which is strongly dependent on extensive collaborations; whenever the projects included a higher diversity of specialty, more interesting viewpoints were found, and overall better results were obtained. In another set of researches (not discussed here), we had the opportunity to collaborate with clinicians and geneticists, where we could provide a "basic science" insight onto genetic diseases that were manifesting themselves at protein level. After a case was identified, the faulty gene was investigated, and we had a look at the (computed) protein structure of the mutated gene. This experience led us to define a new research section where we try to see whether our used in silico methods can provide more precise information on the proteins' mutation effects on its structure.

While in silico and in vitro methods have serious limitations, and in vivo disease models are still far from the reality of pathogenic conditions in human bodies, it is still possible to relate (to some extent) the data obtained from these different methods. We are still a long way from the ideal situation where everything could be computed and there would be no need to perform other experiments, but in order to get closer to that aim, we need to gather more data, and continue to interact between disciplines.

Acknowledgements The authors wish to thank Joulia Alizadeh-Rahrovi, Farnaz Banakar, and Homa Faraji for their valuable help.

\section{Compliance with ethical standards}

Conflict of interest The authors declare to have no conflict of interests.

\section{References}

1. Ahmadi A, Fadaei Y, Shirani M, Rahmani F. Modeling and forecasting trend of COVID-19 epidemic in Iran until May 13, 2020. Med J Islam Repub Iran. 2020;34:27.

2. Al-Qaness MA, Ewees AA, Fan H, Abd El Aziz M. Optimization method for forecasting confirmed cases of COVID-19 in China. J Clin Med. 2020;9(3):674.

3. Petropoulos F, Makridakis S. Forecasting the novel coronavirus COVID-19. PLoS One. 2020;15(3):e0231236.

4. Sarkar K, Khajanchi S, Nieto JJ. Modeling and forecasting the COVID-19 pandemic in India. Chaos Solitons Fractals. 2020;139:110049.

5. Serafin MB, Bottega A, Foletto VS, da Rosa TF, Hörner A, Hörner R. Drug repositioning an alternative for the treatment of coronavirus COVID-19. Int J Antimicrob Agents. 2020;55:105969.

6. Altay O, Mohammadi E, Lam S, Turkez H, Boren J, Nielsen J, et al. Current status of COVID-19 therapies and drug repositioning applications. Iscience. 2020;23:101303.

7. Mahdian S, Ebrahim-Habibi A, Zarrabi M. Drug repurposing using computational methods to identify therapeutic options for
COVID-19. J Diabetes Metab Disord. 2020;1-9. https://doi.org/ 10.1007/s40200-020-00546-9.

8. Mohammadi B, Haghpanah V, Larijani B. A stochastic model of tumor angiogenesis. Comput Biol Med. 2008;38(9):1007-11.

9. Mohammadi B, Haghpanah V, Tavangar SM, Larijani B. Modeling the effect of levothyroxine therapy on bone mass density in postmenopausal women: a different approach leads to new inference. Theor Biol Med Model. 2007;4(1):23.

10. Ebrahimi N, Mehdipour P, Mohebi F, Ghanbari A, Azmin M, Farzadfar F. Improved population health in Iran from 1979 to 2019; Decreasing mortality rates and increasing life expectancy. Arch Iran Med (AIM). 2020;23(2):61-68.

11. Ghafoori S, Keshtkar A, Khashayar P, Ebrahimi M, Ramezani M, Mohammadi Z, et al. The risk of osteoporotic fractures and its associating risk factors according to the FRAX model in the Iranian patients: a follow-up cohort. J Diabetes Metab Disord. 2014;13(1):93

12. Naghavi M, Abajobir AA, Abbafati C, Abbas KM, Abd-Allah F, Abera SF, et al. Global, regional, and national age-sex specific mortality for 264 causes of death, 1980-2016: a systematic analysis for the Global Burden of Disease Study 2016. Lancet. 2017;390(10100):1151-210.

13. Ogurtsova K, da Rocha Fernandes J, Huang Y, Linnenkamp U, Guariguata L, Cho NH, et al. IDF Diabetes Atlas: Global estimates for the prevalence of diabetes for 2015 and 2040. Diabetes Res Clin Pract. 2017;128:40-50.

14. Xu X, Wang G, Zhou T, Chen L, Chen J, Shen X. Novel approaches to drug discovery for the treatment of type 2 diabetes. Expert Opin Drug Discovery. 2014;9(9):1047-58.

15. Xu Q, Wang L, Luo J, Shi D. The hot and potential targets of type 2 diabetes mellitus treatment in recent decade. Curr Drug Targets. 2018;19(1):55-69.

16. DiNicolantonio JJ, Bhutani J, O'Keefe JH. Acarbose: safe and effective for lowering postprandial hyperglycaemia and improving cardiovascular outcomes. Open Heart. 2015;2(1):e000327.

17. Melzig MF, Funke I. Inhibitors of alpha-amylase from plants-a possibility to treat diabetes mellitus type II by phytotherapy? Wien Med Wochenschr (1946). 2007;157(13-14):320-4.

18. Ríos JL, Francini F, Schinella GR. Natural products for the treatment of type 2 diabetes mellitus. Planta Med. 2015;81:975-94.

19. Kim J-S, Kwon C-S, Son KH. Inhibition of alpha-glucosidase and amylase by luteolin, a flavonoid. Biosci Biotechnol Biochem. 2000;64(11):2458-61.

20. Li YQ, Zhou FC, Gao F, Bian JS, Shan F. Comparative evaluation of quercetin, isoquercetin and rutin as inhibitors of $\alpha$-glucosidase. J Agric Food Chem. 2009;57(24):11463-8.

21. Lo Piparo E, Scheib H, Frei N, Williamson G, Grigorov M, Chou CJ. Flavonoids for controlling starch digestion: structural requirements for inhibiting human $\alpha$-amylase. J Med Chem. 2008;51(12):3555-61.

22. Tadera K, Minami Y, Takamatsu K, Matsuoka T. Inhibition of $\alpha$ glucosidase and $\alpha$-amylase by flavonoids. J Nutri Sci Vitaminol. 2006;52(2):149-53.

23. Najafian M, Ebrahim-Habibi A, Hezareh N, Yaghmaei P, Parivar K, Larijani B. Trans-chalcone: a novel small molecule inhibitor of mammalian alpha-amylase. Mol Biol Rep. 2011;38(3):1617-20. https://doi.org/10.1007/s11033-010-0271-3.

24. Najafian M, Ebrahim-Habibi A, Yaghmaei P, Parivar K, Larijani B. Core structure of flavonoids precursor as an antihyperglycemic and antihyperlipidemic agent: an in vivo study in rats. Acta Biochim Pol. 2010;57(4):553-60.

25. Karkhaneh L, Yaghmaei P, Parivar K, Sadeghizadeh M, EbrahimHabibi A. Effect of trans-chalcone on atheroma plaque formation, liver fibrosis and adiponectin gene expression in cholesterol-fed NMRI mice. Pharmacol Rep. 2016;68(4):720-7. 
26. Jalalvand F, Amoli MM, Yaghmaei P, Kimiagar M, EbrahimHabibi A. Acarbose versus trans-chalcone: comparing the effect of two glycosidase inhibitors on obese mice. Archi Endocrinol Metab. 2015;59(3):202-9.

27. Zhuang C, Zhang W, Sheng C, Zhang W, Xing C, Miao Z. Chalcone: a privileged structure in medicinal chemistry. Chem Rev. 2017;117(12):7762-810.

28. Gomes MN, Muratov EN, Pereira M, Peixoto JC, Rosseto LP, Cravo PV, et al. Chalcone derivatives: promising starting points for drug design. Molecules. 2017;22(8):1210.

29. Najafian M, Amini S, Dehestani B, Parivar K, Ebrahim-Habibi A. Thioflavin $\mathrm{T}$ effect in diabetic Wistar rats: reporting the antihyperglycemic property of an amyloid probing dye. Pharmacol Rep. 2015;67(2):364-9. https://doi.org/10.1016/j. pharep.2014.10.013.

30. Jalalvand F, Amoli MM, Yaghmaei P, Kimiagar M, EbrahimHabibi A. Benzothiazole Thioflavin T improves obesity-related symptoms in mice. Period Biol. 2016;118(2):91-7.

31. Groenning M. Binding mode of Thioflavin $\mathrm{T}$ and other molecular probes in the context of amyloid fibrils - current status. J Chem Biol. 2010;3(1):1-18.

32. Gamir-Morralla A, Sacristán S, Medina M, Iglesias T. Effects of thioflavin T and GSK-3 inhibition on lifespan and motility in a caenorhabditis elegans model of tauopathy. J Alzheimers Dis Rep. 2019;3(1):47-57.

33. Alavez S, Vantipalli MC, Zucker DJ, Klang IM, Lithgow GJ. Amyloid-binding compounds maintain protein homeostasis during ageing and extend lifespan. Nature. 2011;472(7342):226-9.

34. Roshanzamir K, Kashani-Amin E, Ebrahim-Habibi A, Navidpour L. Aurones as new porcine pancreatic $\alpha$-Amylase inhibitors. Lett Drug Des Discovery. 2019;16(3):333-40.

35. Navidpour L, Shadnia H, Shafaroodi H, Amini M, Dehpour AR, Shafiee A. Design, synthesis, and biological evaluation of substituted 2-alkylthio-1, 5-diarylimidazoles as selective COX-2 inhibitors. Bioorg Med Chem. 2007;15(5):1976-82.

36. Gilles C, Astier JP, Marchis-Mouren G, Cambillau C, Payan F. Crystal structure of pig pancreatic $\alpha$-amylase isoenzyme II, in complex with the carbohydrate inhibitor acarbose. Eur J Biochem. 1996;238(2):561-9.

37. Yousefi A, Yousefi R, Panahi F, Sarikhani S, Zolghadr AR, Bahaoddini A, et al. Novel curcumin-based pyrano [2, 3-d] pyrimidine anti-oxidant inhibitors for $\alpha$-amylase and $\alpha$-glucosidase: Implications for their pleiotropic effects against diabetes complications. Int J Biol Macromol. 2015;78:46-55.

38. Esmaeili S, Ghobadi N, Nazari D, Pourhossein A, Rasouli H, Adibi $\mathrm{H}$, et al. Curcumin-based antioxidant and glycohydrolase inhibitor compounds: Synthesis and in vitro appraisal of the dual activity against diabetes. Med Chem (Shariqah (United Arab Emirates)). 2020. https://doi.org/10.2174/1573406416666 200506083718

39. Alam F, Shafique Z, Amjad ST, Bin Asad MHH. Enzymes inhibitors from natural sources with antidiabetic activity: A review. Phytother Res. 2019;33(1):41-54. https://doi.org/10.1002/ptr. 6211.

40. Ochieng CO, Nyongesa DW, Yamo KO, Onyango JO, Langat MK, Manguro LA. $\alpha$-Amylase and $\alpha$-glucosidase inhibitors from Zanthoxylum chalybeum Engl. root bark. Fitoterapia. 2020;104719. https://doi.org/10.1016/j.fitote.2020.104719.

41. Kirisanth A, Nafas M, Dissanayake RK, Wijayabandara J. Antimicrobial and alpha-amylase inhibitory activities of organic extracts of selected Sri Lankan bryophytes. Evid Based Complement Alternat Med. 2020;2020:3479851. https://doi.org/ 10.1155/2020/3479851.

42. Bashary R, Vyas M, Nayak SK, Suttee A, Verma S, Narang R, et al. An insight of alpha-amylase inhibitors as a valuable tool in the management of type 2 diabetes mellitus. Curr Diabetes Rev. 2020;16(2):117-36.

43. Etsassala NG, Badmus JA, Waryo TT, Marnewick JL, Cupido $\mathrm{CN}$, Hussein AA, et al. Alpha-glucosidase and alpha-amylase inhibitory activities of novel abietane diterpenes from Salvia africana-lutea. Antioxidants. 2019;8(10):421.

44. Lotter N, Chivandi E, Lembede B, Ndhlala A, Nyakudya T, Erlwanger K. Anti-oxidant activity, alpha-amylase inhibition and toxicity of leaf extracts of cultivated Rapanea melanophloeos (L.) Mez (cape beech). S Afr J Bot. 2019;126:261-4.

45. Barkat AA, Jamal P, Azmi AS, Noorbacha IA, Idris ZM. Potential inhibitors of $\hat{\imath} \pm$-glucosidase and $\hat{\imath} \pm$-amylase enzymes from locally avaialable fruit wastes by solid state fermentation. Biol Nat Resour Eng J. 2019;2(1):56-63.

46. Hichri F, Omri A, Hossan ASM, Ben Jannet H. Alphaglucosidase and amylase inhibitory effects of Eruca vesicaria subsp. longirostris essential oils: synthesis of new 1, 2, 4triazole-thiol derivatives and 1,3, 4-thiadiazole with potential inhibitory activity. Pharm Biol. 2019;57(1):564-70.

47. Lalegani S, Gavlighi HA, Azizi MH, Sarteshnizi RA. Inhibitory activity of phenolic-rich pistachio green hull extract-enriched pasta on key type 2 diabetes relevant enzymes and glycemic index. Food Res Int. 2018;105:94-101.

48. Ojo OA, Afon AA, Ojo AB, Ajiboye BO, Oyinloye BE, Kappo AP. Inhibitory effects of solvent-partitioned fractions of two nigerian herbs (spondias mombin linn. and mangifera indica L.) on $\alpha$ amylase and $\alpha$-glucosidase. Antioxidants. 2018;7(6):73.

49. Kashani-Amin E, Ebrahim-Habibi A, Larijani B, MoosaviMovahedi AA. Effect of neohesperidin dihydrochalcone on the activity and stability of alpha-amylase: a comparative study on bacterial, fungal, and mammalian enzymes. J Mol Recognit. 2015;28(10):605-13. https://doi.org/10.1002/jmr.2473.

50. Kashani-Amin E, Larijani B, Ebrahim-Habibi A. Neohesperidin dihydrochalcone: presentation of a small molecule activator of mammalian alpha-amylase as an allosteric effector. FEBS Lett. 2013;587(6):652-8. https://doi.org/10.1016/j.febslet.2013.01. 022.

51. Kashani-Amin E, Yaghmaei P, Larijani B, Ebrahim-Habibi A. Xanthine derivatives as activators of alpha-amylase: hypothesis on a link with the hyperglycemia induced by caffeine. Obes Res Clin Pract. 2013;7(6):e487-93. https://doi.org/10.1016/j. orcp.2012.07.007.

52. Laffitte A, Neiers F, Briand L. Functional roles of the sweet taste receptor in oral and extraoral tissues. Curr Opin Clin Nutr Metab Care. 2014;17(4):379.

53. San Gabriel AM. Taste receptors in the gastrointestinal system. Flavour. 2015;4(1):1-4.

54. Kashani-Amin E, Sakhteman A, Larijani B, Ebrahim-Habibi A. Introducing a new model of sweet taste receptor, a class $\mathrm{C}$ G-protein Coupled Receptor (C GPCR). 2019;77(3):227-43. https://doi.org/10.1007/s12013-019-00872-7.

55. Kashani-Amin E, Sakhteman A, Larijani B, Ebrahim-Habibi A. Presence of carbohydrate binding modules in extracellular region of class C G-protein coupled receptors (C GPCR): An in silico investigation on sweet taste receptor. Cell Biochem Biophys. 2019;44(6). https://doi.org/10.1007/s12013-019-00872-7.

56. Krieger E, Vriend G. YASARA View - molecular graphics for all devices - from smartphones to workstations. Bioinformatics. 2014;30(20):2981-2.

57. Krieger E, Vriend G. New ways to boost molecular dynamics simulations. J Comput Chem. 2015;36(13):996-1007.

58. Trott O, Olson AJ. AutoDock Vina: improving the speed and accuracy of docking with a new scoring function, efficient optimization, and multithreading. J Comput Chem. 2010;31(2):45561. 
59. Yang L, Cui M, Liu B. Current progress in understanding the structure and function of sweet taste receptor. J Mol Neurosci. 2020. https://doi.org/10.1007/s12031-020-01642-4.

60. DuBois GE, Prakash I. Non-caloric sweeteners, sweetness modulators, and sweetener enhancers. Annu Rev Food Sci Technol. 2012;3:353-80.

61. Pearlman M, Obert J, Casey L. The association between artificial sweeteners and obesity. Curr Gastroenterol Rep. 2017;19(12):64.

62. Khan SA. Artificial sweeteners: safe or unsafe? JPMA J Pak Med Assoc. 2015;65(2):225-7.

63. Fink AL. Protein aggregation: folding aggregates, inclusion bodies and amyloid. Fold Des. 1998;3(1):R9-23.

64. Chiti F, Dobson CM. Protein misfolding, amyloid formation, and human disease: a summary of progress over the last decade. Annu Rev Biochem. 2017;86:27-68.

65. Knowles TP, Vendruscolo M, Dobson CM. The amyloid state and its association with protein misfolding diseases. Nat Rev Mol Cell Biol. 2014;15(6):384-96.

66. Doig AJ, Derreumaux P. Inhibition of protein aggregation and amyloid formation by small molecules. Curr Opin Struct Biol. 2015;30:50-6.

67. Bu X-L, Rao PP, Wang Y-J. Anti-amyloid aggregation activity of natural compounds: implications for Alzheimer's drug discovery. Mol Neurobiol. 2016;53(6):3565-75.

68. Aswathy L, Jisha RS, Masand VH, Gajbhiye JM, Shibi IG. Design of novel amyloid $\beta$ aggregation inhibitors using QSAR, pharmacophore modeling, molecular docking and ADME prediction. Silico Pharmacol. 2018;6(1):12.

69. Young LM, Ashcroft AE, Radford SE. Small molecule probes of protein aggregation. Curr Opin Chem Biol. 2017;39:90-9.

70. Velander P, Wu L, Henderson F, Zhang S, Bevan DR, Xu B. Natural product-based amyloid inhibitors. Biochem Pharmacol. 2017;139:40-55.

71. Wang Q, Yu X, Li L, Zheng J. Inhibition of amyloid- $\beta$ aggregation in Alzheimer's disease. Curr Pharm Design. 2014;20(8):1223-43.

72. Sharma V, Ghosh KS. Inhibition of amyloid fibrillation by small molecules and nanomaterials: strategic development of pharmaceuticals against amyloidosis. Protein Pept Lett. 2019;26(5):31523.

73. Tartaglia GG, Pawar AP, Campioni S, Dobson CM, Chiti F, Vendruscolo M. Prediction of aggregation-prone regions in structured proteins. J Mol Biol. 2008;380(2):425-36.

74. Chennamsetty N, Voynov V, Kayser V, Helk B, Trout BL. Prediction of aggregation prone regions of therapeutic proteins. $\mathrm{J}$ Phys Chem B. 2010;114(19):6614-24.

75. Agrawal NJ, Kumar S, Wang X, Helk B, Singh SK, Trout BL. Aggregation in protein-based biotherapeutics: computational studies and tools to identify aggregation-prone regions. J Pharm Sci. 2011;100(12):5081-95.

76. Beerten J, Schymkowitz J, Rousseau F. Aggregation prone regions and gatekeeping residues in protein sequences. Curr Top Med Chem. 2012;12(22):2470-8.

77. Beerten J, Van Durme J, Gallardo R, Capriotti E, Serpell L, Rousseau F, et al. WALTZ-DB: a benchmark database of amyloidogenic hexapeptides. Bioinformatics. 2015;31(10):1698-700.

78. Perrett S, De Baets G, Schymkowitz J, Rousseau F. Predicting aggregation-prone sequences in proteins. Essays Biochem. 2014;56:41-52.

79. Van Durme J, De Baets G, Van Der Kant R, Ramakers M, Ganesan A, Wilkinson H, et al. Solubis: a webserver to reduce protein aggregation through mutation. Protein Eng Des Sel. 2016;29(8):285-9.
80. Meric G, Robinson AS, Roberts CJ. Driving forces for nonnative protein aggregation and approaches to predict aggregation-prone regions. Annu Rev Chem Biomol Eng. 2017;8:139-59.

81. Sankar K, Krystek SR Jr, Carl SM, Day T, Maier JK, AggScore. Prediction of aggregation-prone regions in proteins based on the distribution of surface patches. Proteins: Struct Funct Bioinf. 2018;86(11):1147-56.

82. Pujols J, Peña-Díaz S, Ventura S. AGGRESCAN3D: Toward the prediction of the aggregation propensities of protein structures. Computational drug discovery and design. Berlin: Springer; 2018. p $427-43$.

83. Prabakaran R, Rawat P, Kumar S, Gromiha MM. ANuPP: A versatile tool to predict aggregation nucleating regions in peptides and proteins. J Mol Biol. 2020. https://doi.org/10.1016/j.jmb. 2020.11.006.

84. Chinisaz M, Larijani B, Ebrahim-Habibi A. A molecular modeling study on full-length insulin: insight into initial events of amyloid formation. Struct Chem. 2014;25(4):1175-85.

85. Alizadeh-Rahrovi J, Shayesteh A, Ebrahim-Habibi A. Structural stability of myoglobin and glycomyoglobin: a comparative molecular dynamics simulation study. J Biol Phys. 2015;41(4):349-66. https://doi.org/10.1007/s10867-015-9383-2.

86. Li A, Daggett V. Characterization of the transition state of protein unfolding by use of molecular dynamics: chymotrypsin inhibitor 2. Proc Natl Acad Sci. 1994;91(22):10430-4.

87. Kabsch W, Sander C. DSSP: definition of secondary structure of proteins given a set of 3D coordinates. Biopolymers. 1983;22: 2577-637.

88. Heinig M, Frishman D. STRIDE: a web server for secondary structure assignment from known atomic coordinates of proteins. Nucleic Acids Res. 2004;32(suppl_2):W500-2.

89. Majumdar I, Krishna SS, Grishin NV. PALSSE: A program to delineate linear secondary structural elements from protein structures. BMC Bioinform. 2005;6(1):1-24.

90. Labesse G, Colloc'h N, Pothier J, Mornon J-P. P-SEA: a new efficient assignment of secondary structure from $\mathrm{C} \alpha$ trace of proteins. Bioinformatics. 1997;13(3):291-5.

91. Taylor WR. Defining linear segments in protein structure. J Mol Biol. 2001;310(5):1135-50.

92. King SM, Johnson WC. Assigning secondary structure from protein coordinate data. Proteins: Struct Funct Bioinf. 1999;35(3): 313-20.

93. Chinisaz M, Ghasemi A, Larijani B, Ebrahim-Habibi A. Amyloid formation and inhibition of an all-beta protein: a study on fungal polygalacturonase. J Mol Struct. 2014;1059:94-100.

94. Azami-Movahed M, Shariatizi S, Sabbaghian M, Ghasemi A, Ebrahim-Habibi A, Nemat-Gorgani M. Heme binding site in apomyoglobin may be effectively targeted with small molecules to control aggregation. Int J Biochem Cell Biol. 2013;45(2):299 307.

95. Chinisaz M, Ebrahim-Habibi A, Yaghmaei P, Parivar K, Dehpour A-R, STUDY OF AMYLOID, FIBRILLATION OF REGULAR INSULIN. Inhibition by aromatic compounds. Iran J Diabetes Metab. 2014;13(4):308-18.

96. Yaghmaei P, Kheirbakhsh R, Dezfulian M, Haeri-Rohani A, Larijani B, Ebrahim-Habibi A. Indole and trans-chalcone attenuate amyloid $\beta$ plaque accumulation in male Wistar rat: in vivo effectiveness of two anti-amyloid scaffolds. Arch Ital Biol. 2013;151(3):106-13.

97. Yaghmaei P, Azarfar K, Dezfulian M, Ebrahim-Habibi A. Silymarin effect on amyloid- $\beta$ plaque accumulation and gene expression of APP in an Alzheimer's disease rat model. DARU J Pharm Sci. 2014;22(1):24.

98. Asadbegi M, Yaghmaei P, Salehi I, Ebrahim-Habibi A, Komaki A. Neuroprotective effects of metformin against $A \beta$-mediated 
inhibition of long-term potentiation in rats fed a high-fat diet. Brain Res Bull. 2016;121:178-85.

99. Asadbegi M, Yaghmaei P, Salehi I, Komaki A, Ebrahim-Habibi A. Investigation of thymol effect on learning and memory impairment induced by intrahippocampal injection of amyloid beta peptide in high fat diet-fed rats. Metab Brain Dis. 2017;32(3):827-39.

100. Taheri P, Yaghmaei P, Tehrani HS, Ebrahim-Habibi A. Effects of eugenol on alzheimer's disease-like manifestations in insulin-and A $\beta$-induced rat models. Neurophysiology. 2019;51(2):114-9.

101. Kheirbakhsh R, Chinisaz M, Khodayari S, Amanpour S, Dehpour A-R, Muhammadnejad A, et al. Injection of insulin amyloid fibrils in the hippocampus of male Wistar rats: Report on memory impairment and formation of amyloid plaques. Neurol Sci. 2015;36(8):1411-6.

102. Chinisaz M, Ebrahim-Habibi A, Dehpour A-R, Yaghmaei P, Parivar K, Moosavi-Movahedi AA. Structure and function of anhydride-modified forms of human insulin: In silico, in vitro and in vivo studies. Eur J Pharm Sci. 2017;96:342-50.
103. Chinisaz M, Ebrahim-Habibi A, Yaghmaei P, Parivar K, Dehpour A-R. Generating local amyloidosis in mice by the subcutaneous injection of human insulin amyloid fibrils. Exp Ther Med. 2014;8(2):405-8.

104. Kheirbakhsh R, Chinisaz M, Amanpour S, Amini S, Khodayari S, Khodayari $\mathrm{H}$, et al. Turmeric effect on subcutaneous insulininduced amyloid mass: an in vivo study. Drug Chem Toxicol. 2017;40(1):1-6.

105. Metkar SK, Girigoswami A, Vijayashree R, Girigoswami K. Attenuation of subcutaneous insulin induced amyloid mass in vivo using Lumbrokinase and Serratiopeptidase. Int J Biol Macromol. 2020;163:128-34.

Publisher's note Springer Nature remains neutral with regard to jurisdictional claims in published maps and institutional affiliations. 